\title{
Risk factors for delayed bleeding after endoscopic submucosal dissection
}

\author{
Ali Kagan Coskun • Mustafa Tahir Ozer • \\ Sezai Demirbas
}

Accepted: 12 June 2014 / Published online: 24 June 2014

(C) Springer-Verlag Berlin Heidelberg 2014

\section{Dear Editor:}

We read with interest the article risk factors for delayed bleeding after endoscopic submucosal dissection for colorectal neoplasms by Terasaki et al. [1] published online in the International Journal of Colorectal Disease. The authors evaluated the risk factors for delayed bleeding after endoscopic submucosal dissection for colorectal neoplasms and found the location of lesions in the rectum as a significant independent risk factor. They also reported that the clinician should keep in mind the severe submucosal fibrosis and the size of the lesion would have decisive influence on the management of endoscopic submucosal dissection for colorectal neoplasms. When we read the article, some questions recurred to our minds. We need an explanation from authors on a few topics.

First, we wonder about body mass index, which was not included in the analysis. As it is known, obesity is an expansion of white adipose tissue with low-grade inflammation [2] and the fibrosis is supposed to be the result of white adipose tissue inflammation in obesity [3]. However, it is being searched whether fibrosis is a causitive agent or a result of inflammation in the white adipose tissue in obese people [4]. In the study, the authors found the rate of lesions with severe fibrosis with delayed bleeding to be higher than that of lesions without bleeding. Therefore, we are curious about the relation between BMI levels of the patients and fibrosis with delayed bleeding.

Second, the authors found the rectum location of the lesion as a significant independent risk factor for delayed bleeding. The rectum vascularization includes branches from the inferior mesenteric artery and branches from the internal iliac

\footnotetext{
A. K. Coskun $(\bowtie) \cdot$ M. T. Ozer $\cdot$ S. Demirbas

Department of Surgery, Gulhane Military Medical Academy,

Ankara, Turkey

e-mail: kagancoskun@gmail.com
}

arteries. This copious vascularization raises the risk of recurrent or delayed bleeding after a procedure. One of the common causes of recurrent bleeding is originating from the middle sacral artery. Its branches pass to the posterior rectum wall. In a case of tumor development through the posterior part of the rectum in sacral or presacral space, it can hypertrophied as a feeder or developed collaterals through the rectum causing a risk of recurrent bleeding [5]. Therefore, we are curious about the locations of the lesions at the rectum. Does anterior, posterior, or lateral location of the lesions make any difference for the delayed bleeding? We also wonder if there is any difference in bleeding patterns of single-lesion versus multiplelesion dissection.

Finally, the authors highlighted important points. We believe that the clarification of the points we mentioned above would make this article more apprehensible and beneficial.

\section{References}

1. Terasaki M, Tanaka S, Shigita K, Asayama N, Nishiyama S, Hayashi N, Nakadoi K, Oka S, Chayama K (2014) Risk factors for delayed bleeding after endoscopic submucosal dissection for colorectal neoplasms. Int J Colorectal Dis (in press)

2. Hotamisligil GS (2006) Inflammation and metabolic disorders. Nature 444:860-867

3. Divoux A, Tordjman J, Lacasa D, Veyrie N, Hugol D, Aissat A, Basdevant A, Guerre-Millo M, Poitou C, Zucker JD, Bedossa P, Clément K (2010) Fibrosis in human adipose tissue: composition, distribution, and link with lipid metabolism and fat mass loss. Diabetes 59:2817-2825

4. Reggio S, Pellegrinelli V, Clément K, Tordjman J (2013) Fibrosis as a cause or a consequence of white adipose tissue inflammation in obesity. Curr Obes Rep 2:1-9. doi:10.1007/s13679-012-0037-4

5. Lee JH, Lee KH, Chung WS, Hur J, Won JY, Lee DY (2004) Transcatheter embolization of the middle sacral artery: collateral feeder in recurrent rectal bleeding. AJR Am J Roentgenol 182(4):1055-1057 